\title{
Publishing negative results to optimize the biopharmaceutical innovation
}

\begin{abstract}
Publishing negative results represents a debate among the scientists and researchers Numerous studies in different countries have shown the importance and the positive impacts of publishing negative data to improve the healthcare and the biopharmaceutical innovation and prolong the lifetime expectance via spreading knowledge even the part of it considered as "negative data". Importantly, the biopharmaceutical innovation is still facing a variety of ethical challenges which gives birth to a lot of criticisms in the healthcare community and in the public. Indeed, nowadays publishing negative research data and clinical trial results disclosure still an ethical issue that requires a convincing rational answer. In this article, we give an ethical sight about the unpublished and undisclosed negative research results and the necessity of their publication. Moreover, the need of publishing trial failures reports remains an important question as well.
\end{abstract}

Keywords: publication, negative results, biopharmaceutical innovation, ethics
Volume 4 Issue 4 - 2017

\author{
Kadour Ghanemi,' Shuangsheng Yan ${ }^{1,2}$ \\ 'Department of Business Management, China Pharmaceutical \\ University, China \\ ${ }^{2}$ Department of Social Science, China Pharmaceutical University, \\ China
}

\section{Correspondence: Shuangsheng Yan, Director of the} Philosophy of Teaching and Research Office, Department of Social Science, International Pharmaceutical Business School, China Pharmaceutical University, China, Tel +86|3305I5I782, Email yss@cpu.edu.cn

Received: July 24, 2017 | Published: August 30, 2017
Abbreviations: GSK, glaxosmithkline; FDA, food and drug administration; MCA, memorial clinical association

\section{Introduction}

In scientific research and clinical experiments, every failure in any trial, unsuccessful outcome or negative results can often be ignored and neglected by the researchers, and frequently it does not receive the satisfaction of the physicians and clinicians since they consider this fail as a point of weakness. ${ }^{1}$ According to the results of a study in the USA, the physicians might consider that this failure can lead to some disadvantages which can affect their practical career and give loss to their economic status and also misrepresent the company reputation and credibility, hence they do not have enough spunk to publish this negative data. ${ }^{2}$ Usually, the good and positive clinical trials receive a big contentment and satisfaction from the researchers and will be posted on the front of the famous journal pages and get a great fame and media advertising in a quick time, while the negative results can be also published but just after a long period in an unsatisfactory way and in a tricky manner. ${ }^{3}$ Sometimes negative results are not published at all. ${ }^{4}$ However, to serve the scientific research field and to complete the general form of the research, the researchers should publish and disclose the results and data whether they are negative or positive results. ${ }^{5}$ In certain cases, the biopharmaceutical companies give the priority to the company benefits and reputation without considering enough the patients and healthcare system benefits, now it is time to push all the clinical trial results to be disclosed (positive or negative). This is what many researchers, scientists, associations and international organizations are working for, in particular in the USA, they even ordered to disclose federally sponsored and funded research trial results to the public in order to share the knowledge and boost the research level. ${ }^{6}$ The data sharing, cooperation between researchers and learning from each other can lead to the patient health improvement and enhance the healthcare system, moreover serving the humanity wellbeing. ${ }^{7}$ The entire research community should adhere to the research ethics under the slogan of "the truth, the whole truth, and nothing but the truth" to achieve the transparency and the clearness between the healthcare team and the patients.

\section{Publishing negative data}

Despite the huge sums the biopharmaceutical companies spend to innovate a new bio drug, they still face a lot of ethical obstacles on publishing data. For instance, a trial results publication average study, which was funded by the National Health Service (NHS) in 2010 , estimated that $50 \%$ of the clinical trial results have never been published; these statistics are based on evidences since 1950s on more than hundreds of researches on several clinical tests. ${ }^{8}$ Sometimes, to avoid the loss of credibility in the public and in the market, the company avoids publishing the negative information. The clinicians should be honest and impartial during the clinical trial results publication, the trial reports must be truthfully shared without any misleading or deception. According to the international committee of medical journal editors, in order to gain the confidence and credibility with the scientific research community, clinicians must be highly ethical in publishing the results of the experiments transparently. ${ }^{9}$ When negative data are honestly and clearly published, it can help to save efforts and a huge amounts of money, because several companies might work at the same time on the same compound, so when the company publish the negative data, the other companies can take that into consideration for the target issues and can reformulate this compound (during a pharmacological study for example), sharing results can also boost the confidence and the trust in the healthcare community especially that publishing improve help the collaboration between each other to innovate better, save lives and advance the healthcare. ${ }^{10,11}$ Moreover, publishing the negative data is a behavior that can help to inform the reader and the patients and give them an overview about the clinical trials methods and how clinical research is conducted and give them a sight about disadvantages that can occur in order to give them the choice regarding a possible participation and avoid exposing them to an inefficient therapy trial and also lead to progress in scientific research in the future..$^{12,13}$

In UK, the British pharmaceutical giant GlaxoSmithKline (GSK) did a clinical trial of an anti-depressant bio drug (seroxat). This research included nine studies in depressed children, some children were provided with (seroxat) and others were provided with placebo 
control, an accurate data examination of the nine studies by the food and drug administration (FDA) and the memorial clinical association (MCA) found out that the (seroxat) have no efficacy in the adolescent depression and that the patients that were provided with an active compound or already stopped taking the (seroxat) had suicide attempt, in contrast those who took placebo have not this suicide thoughts, the noticeable item which the investigators point the finger on is the research results publication, between all this nine studies, only one study result was published by the GSK, this publication mentioned that the bio drug was better than providing the child with a placebo and this bio drug cannot lead to suicide attempt. ${ }^{14}$ Due to this unethical falsification and data mislead and fraud, human life can be exposed to risks and harm, later the GSK will be punished and fall into many problems and judicial troubles in the USA, this lead to a huge sums loss, a credibility and public trust drop leading to company reputation decline..$^{15}$

Recently in the healthcare field, the rate of losses is witnessing a terrible rises due to the lack of publication and report shortage, the healthcare community and the public need more publications of techniques and expenses about the research trial. ${ }^{16,17}$ The most important issue which all the healthcare professionals should take into consideration is that the human being benefits and welfare is more important than the company benefits, the lack of negative results publication is among the biggest healthcare research challenges, several big companies declared that every clinical information (positive or negative) should be published, do not show the reality (negative results) is seen as a fraud, a deception, a non-transparency and a scientific research shame and misconduct which can affect the humanity wellbeing in general. ${ }^{18}$ Indeed, every poor publication or mislead can lead to heavy consequences that can affect the patient health quality. ${ }^{19,20}$ In addition to the bad financial and scientific outcomes which can be caused by misleading publications, it is also a kind of morality violation and ethical rules infringement. ${ }^{21,22}$ Hiding the negative data affects the science in general, the effective way to ameliorate this lamentable situation is the existence of journals and publishers which can disclose and share these negative results with the public. ${ }^{23}$ Journals which are specialized in publishing negative data and providing a space for publishing negative outcomes and unexpected results do exist, for instance The Journal of Negative Results in biomedicine. ${ }^{24}$ However, this is not enough to promote and boost the negative data disclosing, all journals should publish both positive and negative data and should avoid the publication bias. Good examples are represented by the Journal of Cerebral Blood Flow and Metabolism and the Journal of cerebral blood flow and Metabolism. These journals had put special sections for the negative and unexpected results.

\section{Perspectives}

We are at a time when the misleading behaviour and the nondisclosure of the research results and data are totally noticeable. This dilemma did not find persuasive ethical answers yet and gave birth to a huge controversy in the health care area. Indeed, it is among the most substantial issues that have created a big debate within the social and political leaders, clinicians and researchers. Therefore, the whole healthcare team must work according to a moral and ethical way, because the role of the researchers is not only about producing and discovering, but it is also an extremely ethical issue. The contribution of the research results disclosure in developing the health sector and improve patient health is with great advantages thus, the research staff should always think about it. It would be an advanced step if the whole healthcare professionals and researchers adhere to the high ethical standards and awareness, and make their main aim to enhance the patient's health and just focus on serving the patients wellbeing and improve the healthcare. It would also be a sophisticated behavior if they always think about the future and have long-term thinking and consider the improvements that can occur in the health sector rather than thinking only about the near future and the short term. In this way, we will observe the welfare spread, the honesty, the transparency between the patients and healthcare teams and recognize the prevalence of the cooperative spirit between researchers for serving the health sector, the public and the whole humanity interests.

\section{Acknowledgements}

We acknowledge the Jiangsu Overseas Research \& Training Program for University Prominent Young \& Middle-aged Teachers. Kadour Ghanemi is the recipient of a full scholarship from the China Scholarship council.

\section{Conflict of interest}

The authors declare that there is no conflict of interest.

\section{References}

1. Kannan S, Gowri S. Contradicting/negative results in clinical research: Why (do we get these)? Why not (get these published)? Where (to publish)? Perspect Clin Res. 2014;5(4):151-153.

2. Fanelli D. Do pressures to publish increase scientists' bias? An empirical support from US States Data. PLoS One. 2010;5(4):e10271.

3. Gordon DJ, Lauer MS. Publication of trials funded by the National Heart, Lung, and Blood Institute. N Engl J Med. 2013;370(8):782.

4. Carroll J. Trials on Trial: The Push for Clinical Data Disclosure. Biotechnol Healthc. 2004;1(5):51-55.

5. Edlavitch SA. Publishing negative findings and the challenge of avoiding type II errors in studies of suspect teratogens: Example of a recent ondansetron publication. Reprod Toxicol. 2017;67:125-128.

6. Increasing Access to the Results of Federally Funded Scientific Research. USA: Executive Office of the President, Office of Science and Technology Policy; 2016.

7. Hudson KL, Collins FS. Sharing and Reporting the Results of Clinical Trials. JAMA. 2015;313(4):355-356.

8. Song F, Parekh S, Hooper L, et al. Dissemination and publication of research findings: an updated review of related biases. Health Technology Assessment. 2010;14(8):1-93.

9. De Angelis C, Drazen JM, Frizelle FA, et al. Clinical trial registration: a statement from the International Committee of Medical Journal Editors. Lancet. 2004;364(9438):911-912.

10. Prinz P, Schlange T, Asadullah K. Believe it or not: how much can we rely on published data on potential drug targets? Nat Rev Drug Discov. 2011;10(9):712-713.

11. The editors of the lancet. Protocol review at the lancet: 1997-2015 Lancet. 2015;386(10012):2456-2457.

12. Chalmers I. Under reporting research is scientific misconduct. JAMA 1990;263(10):1405-1408.

13. Hayes A, Hunter J. Why is publication of negative clinical trial data important? Br J Pharmacol. 2012;167(7):1395-1397.

14. Eaton ML. Ethical Issues Associated with Pharmaceutical Innovation, in Business Ethics of Innovation. In: Hanekamp, Wütscher, editors. Germany: Springer Berlin Heidelberg; 2007. p. 52-53. 
15. Dyer O. GlaxoSmithKline faces US lawsuit over concealment of trial results. BMJ. 2004;328(7453):1395.

16. Simera I, Moher D, Hirst A, et al. Transparent and accurate reporting increases reliability, utility, and impact of your research: reporting guidelines and the EQUATOR Network. BMC Medicine. 2010;8:24.

17. Chalmers I, Glasziou P. Avoidable waste in the production and reporting of research evidence. Lancet. 2009;374(9683):86-89.

18. Easterbrook PJ, Berlin JA, Gopalan R, et al. Publication bias in clinical research. Lancet. 1991;337(8746):867-872.

19. Simes RJ. Publication bias: the case for an international registry of clinical trials. Journal of Clinical Oncology. 1986;4(10):1529-1541.
20. Eyding D, Lelgemann M, Grouven U, et al. Reboxetine for acute treatment of major depression: systematic review and meta-analysis of published and unpublished placebo and selective serotonin reuptake inhibitor controlled trials. BMJ. 2010;341:c4737.

21. Savitz DA. Failure to publish results of epidemiologic studies is unethical. Epidemiology. 2000;11(3):361-363.

22. Moher D. Reporting research results: a moral obligation for all researchers. Can J Anaesth. 2007;54(5):331-335.

23. De Maria AN. Publication bias and journals as policemen. J Am Coll Cardiol. 2004;44(8):1707-1708.

24. Pfeffer C, Olsen BR. Editorial: journal of negative results in biomedicine. J Negat Results Biomed. 2002;1:2. 